\title{
Toothpaste Brands -A Study of consumer behavior in Bangalore city
}

\author{
*G. Vani ${ }^{1}$, M. Ganesh Babu², N. Panchanatham ${ }^{3}$ \\ ${ }^{1}$ Asst. Professor, Acharya Institute of Technology, Solladevanahalli \\ ${ }^{2}$ Assistant Manager, ICICI Bank, Bangalore, 129/2, AGBG Layout Chikkabanavara \\ ${ }^{3}$ Dept Head, Dept of Business Administration, Annamalai University, Chidambaram, Tamilnadu \\ *gvani3333@yahoo.co.in
}

\begin{abstract}
Consumer is king' -the statement carries profound truth in it. Today the success of any firm depends upon the satisfaction of consumers. For satisfying the consumers the firm should know about the behavior of the consumers. In these circumstances understanding consumer is a very difficult task because of the changing technology, innovation, and changes in life style. Researchers conducted many research in this area, and they given only few suggestion, but there is no final conclusion. As per the ideas given by the researchers, there are two factors influencing the consumers such as intrinsic and extrinsic factors. It is difficult to classify consumers by conventional demographic factors and unless their thought process and buying behavior are fully understood, decisions on product designs and packaging, branding and distribution channels are likely to be misplaced. With the inevitability of change looming large over the horizon, Indian companies must learn from their western counterparts; not only to identify the sources, timing and direction of the changes likely to affect India, but also the new competencies and perspective that will enable them to respond to these changes, comprehensively and effectively. This study mainly focus on understanding the external factors like demographic, social, cultural ,price, quality ,product attributes etc for buying toothpaste. The market share of any product is highly determined by the purchasing behavior of the consumers. Following study is conducted by the researcher to find out the behavior of the consumers, to analyze the preference of consumers, \& consumer awareness. Descriptive research design was adopted and the data is collected through primary and secondary sources. The method adopted for conducting survey is questionnaire; Simple random sampling technique was adopted for selecting the consumers.
\end{abstract}

Key words: Consumer behavior, Toothpaste buying pattern, Toothpaste awareness, Promotion impact, Attribute impact.

\section{Introduction}

Consumer behavior is stated as the behavior that consumer display in searching for, purchasing, using, evaluating, and disposing of products, services and ideas that they expect will satisfy their needs. The study of consumer behavior is concerned not only with what consumers buy, but also with why they buy it, when and how they buy it, and how often they buy it. It is concerned with learning the specific meanings that products hold for consumers. Consumer research takes places at every phase of consumption process, before the purchase, during the purchase and after the purchase. According to Philip Kotler defined consumer behavior as "all psychological, social and physical behavior of potential customers as they become aware of evaluate, purchase, consume and tell other about products and services". The scope of consumer behavior includes not only the actual buyer and his act of buying but also various roles played by different individuals and the influence they exert on the final purchase decision .Individual consumer behavior is influenced by economic, social, cultural, psychological, and personal factors.

\subsection{Consumer purchase decision}

A decision is the selection of an action from two or more alternative choices. Consumer decision to purchase the goods from the available alternative choice is known as "consumer purchase decision". The various options of the consumer may be classified into five main types of decisions. They are what to buy, how much to buy, where to buy, when to buy, how to buy. The participants in the buying decisions may be classified as the initiator, influencer, decider, buyer and users. The marketing people should initiate the participants in the purchase decision to make the purchases of the product at different marketing strategies. There are number of reasons why the study of consumer behavior developed as separate discipline. Marketers had long noted that consumer did not always act or react, as marketing theory would suggest. The size of the consumer market in the country was vast and constantly expanding: 
millions of dollars were being spent on goods and services by millions of people. Consumer preferences were changing and becoming highly diversified.

\subsection{Indian Oral Care Industry}

Many people in India still clean their teeth with traditional products like Neem twigs, salt, ash, tobacco or other herbal ingredients. Average all India per capita consumption of toothpaste is a dismal 82gms. The dentist to population ratio is a critically low 1:35000 in the country. This results in low oral hygiene consciousness and widespread dental diseases. Less than $15 \%$ of the Indian toothpaste users brush twice a day. Colgate and Hindustan Lever together account for over $85 \%$ of the organized toothpaste market. Red and Black toothpowder still accounts for $35 \%$ of the toothpowder market. In toothpowders, Colgate and Dabur are the leading players sharing between them $75 \%$ of the market

\section{Review of literature}

\subsection{Consumer behavior}

Consumer behavior has been always of great interest to marketers. The knowledge of consumer behavior helps the marketer to understand how consumers think, feel and select from alternatives like products, brands and the like and how the consumers are influenced by their environment, the reference groups, family, and salespersons and so on. A consumer's buying behavior is influenced by cultural, social, personal and psychological factors. Most of these factors are uncontrollable and beyond the hands of marketers but they have to be considered while trying to understand the complex behavior of the consumers. In this study, the researcher emphasizes the importance of lifestyle and its impact on the buyer behavior.

\subsection{Consumer Personality Factors}

There are two factors mainly influencing the consumers for decision making: Risk aversion and innovativeness. Risk aversion is a measure of how much consumers need to be certain and sure of what they are purchasing (Donthu and Gilliland, 1996).Highly risk adverse consumers need to be very certain about what they are buying. Whereas less risk adverse consumers can tolerate some risk and uncertainty in their purchases. The second variable, innovativeness, is a global measure which captures the degree to which consumers are willing to take chances and experiment with new ways of doing things (Donthu and Gilliand, 1996).The shopping motivation literature is abound with various measures of individual characteristics (e.g., innovative, venturesome, cosmopolitan, variety seeking), therefore, innovativeness and risk aversion were included in this study to capture several of these traits. Measures by Donthu and Gilliland (1996) were used to measure innovativeness and risk aversion.

2.3 Perception: Perception is a mental process, whereby an individual selects data or information from the environment, organizes it and then draws significance or meaning from it.

\subsection{Perceived fit}

Perceived fit is an attitudinal measure of how appropriate a certain channel of distribution is for a specific product .Morrison and Roberts (1998) found that consumer's perception of the fit between a service/product and a channel is very influential in determining whether they will consider using that channel for a specific service. In fact, perceived fit was found to be more important than consumer's preferences for the distribution method or service.

\subsection{Product Class knowledge}

Product class knowledge is a measure of consumers perceptions of how much they know about a specific class of products (eg.,cars)This type of measure is consistent with what Brucks(1985) called subjective knowledge, that is, consumers self-perceptions of knowledge levels. This is often contrasted with objective knowledge, which is what consumers actually know. Park and Lessing (1981) proposed that subjective knowledge provides a better understanding of consumers decision making processes because consumers level of confidence in their search and decision making behavior, independent of their objective knowledge.

\subsection{Product type}

Past research indicates that consumers purchase and channel decisions might be influenced by the type of product being investigated (Cox and Rich 1964:Lumpkin and Hawes 1985;Morrison and Roberts 1998:Papadopoulos 1980:Prasad 1975:Sheth 1983: Thompson 1971).In particular , these authors state 
that certain products might be more appropriate for one channel or another, which ultimately influences consumers channel preference and choice.

\subsection{Quality}

It is our aim to provide the best product for the consumer and we believe that if the products have quality the consumer will pay the price, says Amal pramanic, regional business director .Oral-B

\subsection{Packaging}

Packaging establishes a direct link with the consumers at the point of purchase as it can very well change the perceptions they have for a particular brand. A product has to draw the attention of the consumers through an outstanding packaging design. Earlier packaging was considered only a container to put a product in, but today, research in to the right packaging is beginning at the product development stage itself. Packaging innovation has been at the heart of Dabur's attempt to rap with the urban consumers. It spends large sums annually on packaging research.-"We have been laying emphasis on aesthetics, shelf appeal and convenience for consumer"' says Deepak Manchandra, manager packaging development

\subsection{Promotion}

The greatest challenge faced by companies today is holding and increasing their market share and value. This is always a strenuous exercise and one of the tools for the same is marketing. There is no specific game rule available for using these marketing tools. The reason is: each promotional tool has its own characteristics.

\subsection{Familiarity with a channel}

Consumer's familiarity with a channel is a measure of the general experience they have with purchasing products through specific channels (i.e.. catalog, internet, and bricks-and-mortar retailer). Through frequent use consumers should become accustomed to using the channel, which reduces their apprehension and anxiety in purchasing products through the channel.

\subsection{Brand Awareness}

According to Rossiter and Prey (1987), brand awareness precedes all other steps in the buying process. A brand attitude cannot be performed, unless a consumer is aware of the brand. In memory theory, brand awareness is positioned as a vital first step in building the bundle of associations which are attached to the brand in memory (Stokes, 1985).

\subsection{Family influence}

A family exerts a complex influence on the behaviors of its members. Prior family influence research has focused on intergenerational rather than intergenerational influence in consumer generationalisation. As has been compellingly demonstrated, parents influence children (Moore, Wilkie, and Lutz2002; Moschis 1987).Yet, consumption domains clearly exist where sibling efforts may also be exerted

\subsection{Shopping motives}

Shopping motives are defined as consumer's wants and needs as they relate to outlets at which to shop. Two groups of motives, functional and nonfunctional, have been proposed by Sheth (1983). Functional motives are associated with time, place, and possession needs and refer to rational aspects of channel choice. Whereas nonfunctional motives relate to social and emotional reasons for patronage. The functional motives included: convenience, price comparison, merchandise assortment. The nonfunctional motives entail: recreation. The purpose of the study is

1. To examine the external factors influencing purchase decisions

2. To examine the consumer awareness of toothpaste

3. To find out how promotional schemes are influencing the consumers

4. To examine how the product attributes influencing the consumer buying toothpaste

\section{Research Methodology:}

Research methodology is the process of solving the problem systematically by research. The objective of the study is to solve the problem by using available data. 


\subsection{Research Design}

Research design is a detailed blue print used to guide the research study towards its objectives. In this study the researchers used descriptive design.

\subsubsection{Descriptive research design}

Descriptive research can be either quantitative or qualitative. It can involve collections of quantitative information that can be tabulated along a continuum in numerical form, such as scores on a test or the number of times a person chooses to use a-certain feature of a multimedia program, or it can describe categories of information such as gender or patterns of interaction when using technology in a group situation. Descriptive research involves gathering data that describe events and then organizes, tabulates, depicts, and describes the data collection (Glass \& Hopkins, 1984). It often uses visual aids such as graphs and charts to aid the reader in understanding the data distribution. Because the human mind cannot extract the full import of a large mass of raw data, descriptive statistics are very important in reducing the data to manageable form. When in-depth, narrative descriptions of small numbers of cases are involved, the research uses description as a tool to organize data into patterns that emerge during analysis. Those patterns aid the mind in comprehending a qualitative study and its implications.

\subsection{Sample technique}

Sample is the fraction of the population; sampling is a technique or a method of selection of samples. The researcher in carrying out this research adopted the most appropriate sampling technique for research that is the simple random technique.

\subsubsection{Simple random sampling}

Simple random sampling method, it is assumed that each and every unit in the population has equal chance of occurrence or equal probability of occurrence. In other words the sampling units are selected randomly. An unbiased random selection of individuals is important so that in the long run, the sample represents the population. However, this does not guarantee that a particular sample is a perfect representation of the population. Simple random sampling merely allows one to draw externally valid conclusions about the entire population based on the sample. Conceptually, simple random sampling is the simplest of the probability sampling techniques. It requires a complete sampling frame, which may not be available or feasible to construct for large populations. Even if a complete frame is available, more efficient approaches may be possible if other useful information is available about the units in the population. The researchers have taken 200 samples randomly from the total population. Primary sources of data collected through questionnaire, magazines, journals and website are referred as a secondary source.

\subsection{Instrument Design}

\subsubsection{Method adopted for communication}

Personal interview is the method of contact used with the respondents. Personal interviewing method is used because sample size is relatively small and interviewer can ask more questions.

\subsubsection{Structure of the instrument}

For collecting primary data, method used is questionnaire. It is the most popular method used when the population and sample size are large. A questionnaire includes a number of questions, printed in proper sequence, for presenting to respondents for their answers. Each question is contributing to research objectives. Questionnaire was designed with most of closed ended questions and only few open ended question. It was designed to cater to all areas and aspects of the study.

\subsection{Data analysis and Interpretation}

The data has been collected with the help of questionnaire. And it has been analyzed and interpreted with the help of tables along with relevant descriptions. Appropriate treatment has been done to the raw data and logical conclusions are drawn based on the findings. 


\section{Data analysis and interpretation}

Table-1: Demographic Variable

\begin{tabular}{lcc}
\hline Demographic variable & Number of respondents & Perce \\
\hline Age (Years) & & \\
$7-18$ & 40 & 20 \\
$18-25$ & 60 & 30 \\
$25-30$ & 40 & 20 \\
$30 \&$ above & 60 & 30
\end{tabular}

\section{Gender}

Male

Educational

Qualification

Up to $10+2$

Up to graduation

PG/Higher education

\section{Status}

Student

Professional

House wife

$60-30$

Businessman

$40 \quad 20$

\section{Monthly income}

Below 5000

$20-10$

Rs.5000-Rs. 9000

$40-20$

Rs.9000-11,000

$80-40$

Above Rs.11,000

$60-30$

Table-2: Toothpaste Usage Rate

\begin{tabular}{lcc}
\hline Usage rate & Number of respondents & Percentage \\
\hline Yes & 160 & 80 \\
No & 40 & 20 \\
\hline
\end{tabular}

With a view to find the usage of toothpaste, the data pertaining to this is presented in table 2 . Based on this survey $80 \%$ of the respondents using toothpaste in Bangalore city and $20 \%$ using like toothpowder and mouthwash etc

Table-3: Consumer Brushing Pattern

\begin{tabular}{ccc}
\hline Brushing frequency & Number of respondents & Percentage \\
\hline Once & 120 & 60 \\
Twice & 60 & 30 \\
Thrice & 20 & 10 \\
\hline
\end{tabular}

With a view to find the brushing frequency of consumer, the data pertaining to this is presented in table 3 . An examination of the data reveals that $60 \%$ of the consumers brushing once, $30 \%$ of the consumers brushing twice, and 10\%brushing thrice. So the frequency of brushing was less in Bangalore city, but as per the dentist advice 2 times brushing is compulsory for avoiding dental problem. Normally Indian people are not giving much importance to oralcare, so the share of oral care industry is less in India when compare to developed countries 
Table-4: Frequency of Purchase

\begin{tabular}{lcc}
\hline Per month usage & Number of respondents & Percentage \\
\hline One & 40 & 20 \\
Two & 100 & 50 \\
More than two & 60 & 30 \\
\hline
\end{tabular}

By having a view to find that frequency of purchasing toothpaste, the data pertaining to this is presented in the table 4. An examination of the table reveals that most of the consumers buying toothpaste twice in a month, more than two times in a month, and once in a month. Of the respondents $50 \%$ of them purchase twice, $30 \%$ of the respondents purchase more than twice and $20 \%$ of them purchase once in a month.

Table-5: Awareness of Brands

\begin{tabular}{ccc}
\hline Brands & Number of respondents & Percentage \\
\hline Colgate & 108 & 54 \\
Close Up,Pepsodent & 50 & 25 \\
Dabur & 12 & 06 \\
Anchor & 08 & 04 \\
Ajanta & 06 & 03 \\
Others & 16 & 08 \\
\hline
\end{tabular}

With a view to find that awareness of toothpaste brand, the data pertaining to this is presented in table 5 . An examination of the table reveals that most of the people aware of Colgate, Close-up, Pepsodent, Dabur, Anchor and Ajanta. Before some time Colgate was the generic name for toothpaste, this is the main reason, most of the respondents (54\%) aware of Colgate. 25\% respondents aware of Closeup and Pepsodent(recently launched by HLL company),Dabur, Anchor, \& Ajanta is a Indian based company have a awareness level of $6 \%, 4 \%, \& 3 \%$ and ( $8 \%$ )respondents aware of by other brands

Table-6: Usage of Toothpaste Brands

\begin{tabular}{ccc}
\hline Usage of brand so far & Number of respondents & Percentage \\
\hline Two & 60 & 30 \\
Three & 100 & 50 \\
More than three & 40 & 20 \\
\hline
\end{tabular}

To identify the usage of different brand, the data pertaining to that is presented in the table 6.An examination of the table reveals that most of the consumers used 3 brands, two brands, and more than 3 brands. Of the respondents $50 \%$ of them used 3 brands, $30 \%$ of the respondents used 2 brands, and $20 \%$ of them used more than 3 brands.

Table-7: Dentist Recommendation for Buying Toothpaste

\begin{tabular}{lll}
\hline Dentist Recommendation & Number of respondents & Percentage \\
\hline $\begin{array}{l}\text { I am using toothpaste as per } \\
\text { Dentist advice }\end{array}$ & 80 & 40 \\
$\begin{array}{l}\text { Taste makes me to } \\
\begin{array}{l}\text { Change brand } \\
\text { I am not interested in } \\
\text { oral care }\end{array}\end{array}$ & 60 & 30 \\
$\begin{array}{l}\text { I feel it is a sales } \\
\text { promotion technique }\end{array}$ & 20 & 10 \\
& 40 & 20 \\
\hline
\end{tabular}

With a view to find the dentist recommendation for buying toothpaste, the data pertaining to this is presented in table 7 . Of the total respondents $40 \%$ of the respondents are ready to accept dentist suggestion, $30 \%$ of the respondents are changed their brand due to unlikely taste, $10 \%$ of the respondents are not interested in oral care,20\% of the respondents felt that this is one of the sales promotion technique backed by the company for increasing sales. 
Table-8: Factors Which Makes Consumer to Buy Toothpaste

\begin{tabular}{ccc}
\hline Factors & Number of respondents & Percentage \\
\hline Price & 80 & 40 \\
Availability & 62 & 31 \\
Packaging & 30 & 15 \\
Others & 28 & 14 \\
\hline
\end{tabular}

With a view to find the reasons to buy toothpaste, the data pertaining to this is presented in table 8 . An examination of the table reveals that, consumers are influenced by the price, availability and Packaging. Of the total respondents $40 \%$ of them influenced by the price, $31 \%$ influenced by the availability, $15 \%$ influenced by the packaging, and $14 \%$ influenced by other factors

When the respondents were asked to mention the factors which motivate them to buy a particular brand of toothpaste their replies are mostly price and availability.

Table-9: Preference of Toothpaste

\begin{tabular}{lcc}
\hline Preference & Number of respondents & Percentage \\
\hline Brand & 80 & 40 \\
Quality & 60 & 30 \\
Flavor & 40 & 20 \\
Others & 20 & 10 \\
\hline
\end{tabular}

With a view to find the reason to buy toothpaste, the data pertaining to this is presented in table 9.An examination of the table reveals that, most of the consumers preferred brand, quality, and flavor. In the above table $40 \%$ of the respondents preferred brand name,30\% of the respondents preferred quality, $20 \%$ of the respondents preferred flavor, and $10 \%$ of the respondents preferred other factors. Brand name played a vital role in selection of toothpaste in Bangalore city.

Table-10: Preference of an Attribute

\begin{tabular}{lcc}
\hline Attribute & Number of respondents & Percentage \\
\hline Healthy tooth\& gums & 60 & 30 \\
Long lasting freshness & 20 & 10 \\
Prevention of tooth decay & 40 & 20 \\
Whiteness & 30 & 15 \\
Use of natural herbs & 36 & 18 \\
Good foam & 14 & 07 \\
\hline
\end{tabular}

With a view to find the reasons to buy a toothpaste based on attribute, the data pertaining to this is presented in table 10.An examination of the table reveals that, most of the consumers preferred healthy tooth \& gums, prevention of decay, natural herbs, whiteness, freshness, and foam. The above table clearly shows that $30 \%$ of the respondent's preferred healthy tooth, $20 \%$ respondents preferred prevention of tooth decay, 18\%respondents preferred natural herbs, $15 \%$ preferred whiteness, $10 \%$ preferred freshness, and 7\% preferred good foam.

Table-11: Person who Influenced Consumer to Purchase Toothpaste

\begin{tabular}{lcc}
\hline Persons & Number of respondents & Percentage \\
\hline Friends & 40 & 20 \\
Kids & 30 & 15 \\
Parents & 80 & 40 \\
Spouse & 40 & 20 \\
Self & 10 & 05 \\
\hline
\end{tabular}

With a view to find the persons who influenced consumer to purchase toothpaste, the data pertaining to this is presented in table 11. An examination of the table reveal that, the people who influenced more are, parents, friends, spouse, kids and self decision. Based on the above data, $15 \%$ kids are influencing the 
parents for buying particular brand, parents are the main deciding authority for buying toothpaste(40\%), spouse and friends are equally influencing (20\%) and 5\% decide them self.

Table-12: To Which Mode of Promotion Consumer gets Attracted

\begin{tabular}{lcc}
\hline Mode of promotion & Number of respondents & Percentage \\
\hline Advertisement & 90 & 45 \\
Celebrity & 50 & 25 \\
Banner & 40 & 20 \\
Others & 20 & 10 \\
\hline
\end{tabular}

With a view to find out which mode of promotion consumer gets attracted, the data pertaining to this is presented in table 12.An examination of the table reveals that, most of the consumers preferred advertisement, celebrity, banners.Majority of the respondents $45 \%$ preferred advertisements, $25 \%$ of the respondents preferred celebrity endorsements, $20 \%$ preferred banners, and $10 \%$ preferred other mode of promotion. Advertisement creates attention and stimulates the consumer to buy a particular brand.

Table-13: Factors Which Makes Consumer to Buy Toothpaste

\begin{tabular}{lcc}
\hline Promotion tools & Number of respondents & Percentage \\
\hline Gift & 70 & 35 \\
Discount & 40 & 20 \\
Extra quantity & 50 & 25 \\
Price off & 30 & 15 \\
Others & 10 & 05 \\
\hline
\end{tabular}

By having a view to find the promotion tools preferred by consumer, the data pertaining to this is presented in table 13. An examination of the above data reveals that, most of the consumers preferred gift, extra quantity, discount, price off. Above table indicates that, gift attracted more respondents(35\%) $25 \%$ of the respondents preferred extra quantity, $20 \%$ preferred discounts, $15 \%$ preferred price off and $5 \%$ preferred other tools. Sales promotion tool especially gift attracted more respondents.

Table-14: Switching to Other Brand

\begin{tabular}{lcc}
\hline Reason for switching & Number of respondents & Percentage \\
\hline Impact of packaging & 20 & 10 \\
Price rise of current brand & 32 & 16 \\
Scheme of brands & 36 & 18 \\
Advertisement impact & 40 & 20 \\
Consumer brand is not available & 20 & 10 \\
To try new option & 28 & 14 \\
Influence by other & 24 & 12 \\
\hline
\end{tabular}

With a view to find the reasons for switching to other brand, the data pertaining to this is presented in table 13.An examination of the table reveals that, most of the consumers switches to other brand due to strong advertisement impact; next factor was scheme available with product like discount, free gift, price off etc. Due to sudden increase in price also makes the respondents to switch; some consumers always have a mindset like laggards to try new options available in the market. Kids also influencing the parents to buy a particular brand, not only kids and also friends, relatives, wife etc. sometimes consumers are attracted by packaging to switch. Non availability of brand is one more reason to brand switching. In this analysis $20 \%$ respondents changed to other brand due to advertisement impact, $18 \%$ respondents due to scheme (offer), $16 \%$ respondents changed due to price rise, $14 \%$ respondents switched to other brand to try new options, $12 \%$ respondents due to the influence of others, while other $10 \%$ respondents switched to other brand due to better packaging, and 10\% respondents changed non-availability of product in the market. 


\section{Findings}

\subsection{Demographic factor}

Based on this study demographic factor like age, gender, education, status, and income influence people indirectly for decision making. This is supported by following evidence.

Demographic factors play a major role in children's power to influence their parents. For example, Foxman et al. (1989) argue that age is a relevant variable as older children are presumed to be more knowledgeable about products and family needs. This is mainly due to their increase in cognitive development (Piaget, 1972). However, findings on whether product knowledge has a positive impact on teenagers' influence differ (Beatty and Talpade, 1994). Adolescents were found to have greater influence in concept-oriented families, and if they had better grades (Foxman et al., 1989). Also, parental employment status (single versus dual income) appears to affect teens' influences for some product categories (stereo phones) but not for others (TVs, VCRs, furniture) (Beatty and Talpade, 1994). For instance, adolescents from traditional homes, whose mothers have a career, are more influential in family decision making, possibly due to guilt on the mothers' part (Lee and Beatty, 2002).When trying to influence their parents, children use different types of influence, e.g. bargaining, persuasion, emotional, and request strategy. According to importance and time frame of the presumed purchase, six kinds of response strategies are normally used by parents (bargaining, persuasion, emotional, expert, legitimate, and directive strategy) (Palan and Wilkes, 1997).

\subsection{Usage}

Based on this study $80 \%$ of the consumers using toothpaste in Bangalore city. $50 \%$ of the respondents are brushing twice in a day than once and thrice. When compare to other products like toothpowder and mouth wash, the availability of toothpaste is more in the market and also the package size is convenient for the consumer. So the usage rate is high for toothpaste. This also supported by following review.

Assunçao and Meyer (1993) showed that consumption increases with inventory, not only because of the stock pressure from inventory holding costs, but also because higher inventories give consumers greater flexibility in consuming the product without having to worry about replacing it at high prices. Chiang (1995) found no category expansion effect in the detergent category. Wansink and Deshpandé (1994) showed in a lab study that promotional activity might cause consumers to consume a stockpiled product more quickly. The research performed by Wansink (1996) demonstrated that larger package sizes influence the usage volume of usage variant products, partially because larger packages are perceived to be less expensive to use (lower perceived unit costs).

\subsection{Awareness}

Based on this study the awareness level of toothpaste brand was less in Bangalore city People knows only the popular brands like Colgate, Pepsodent and Close-up. So they purchase only known brand.

In Bangalore city most of the respondents aware of Colgate then Closeup and Pepsodent then regional players like Dabur, Anchor, and Ajanta. This is supported by the following review.

Most of the respondents used 3 brands, two brands, and three. Due to Indian family set up most of the consumers using only one common paste for the entire family. Oral care awareness and brand awareness is less in Bangalore city. Product awareness is an important factor for buying a product. The oral care awareness level is less in India, when compare to other counters like Europe and Thailand. Per capita consumption of toothpaste is only $70 \mathrm{gm}$ in India. In oral care toothpowder, toothpaste and toothbrush dominating the Indian market but in other countries mouth spray, mouth wash products also dominate in the market. Still in India rural area people are using neem and tobacco for brushing. So the manufacturing companies and government both are responsible for creating awareness through advertising campaign.

Brand awareness can also effect decisions about brands within the consideration set (Hoyer and Brown, 1990; and Keller, 1993). Consumers may employ heuristic (decision rule to buy only familiar well, established brands (Riselaus, 1971; and Jacoby et al; 1977, both sited in Keller, 1993). Consumers do not always spend a great deal of time making purchase decisions in a study of pre purchase search for laundry, Hoyer (1984) found that the median number of packages- store was around 1:2 before a selection was made. Dickson and Sawyer (1986) found that purchases such as coffee toothpaste and 
margarine, the consumer took an average 12 seconds from the time of first looking at the shelf's to the time they placed in their trolley.

Hoyer and Brown (1990) designed a controlled experiment probe the role of brand awareness in the process of consumer choice for the purchase of peanut, butter, whose results revealed that brand awareness was a dominant factor in both initial (trial) and repeat purchase decisions even when the quality of the selected brand was inferior to that of the other brands.

\subsection{Frequency of purchase}

Based on this study frequency of purchasing is based on the brushing habit and members in the family. Most of the respondents, buying once in a month, twice and thrice. So frequency of purchasing is mainly based on usage rate and promotional effect. This is supported by following review.

The study of Fader and Lodish (1990) implied a positive relationship between high frequency of purchase and promotional elasticity. Based on Bawa and Shoemaker (1987), Narasimhan et al. (1996) hypothesized that shorter consumer inter purchase time's result in more brand switching because the consumer must live with the consequences of buying a less preferred brand for a shorter period. In addition Narasimhan et al. conjectured that interpurchase times are related to purchase acceleration. Long inter purchase times discourage acceleration because the stockpiled product must be stored for a longer period of time. This was supported by empirical findings. Bell et al. (1999) found less stockpiling for often purchased products.

\subsection{Dentist's advice}

Based on this survey most of the respondents accepted the advice of dentist to avoid dental problem, some respondents changed their brand due to taste problem, few respondents ignored the dentist advice because they felt that this is a sales promotion technique backed by company, some are not interested in oral care. The dentist to population ratio is a critically low 1:35000 in the country. This results in low oral hygiene consciousness and widespread dental diseases.

So the Government and company is responsible for creating awareness through dental campaign to avoid dental problem and increase the consumption of toothpaste in India

\subsection{Price}

Based on this survey, most of the respondents are influenced by price then availability, and then packaging .For increasing the price of a product the company should consider the views of consumer otherwise the consumer switch over to competitor product. This is supported by the following review.

Vani, Ganesh, and Panchanatham(2009) discussed the price of toothpaste in their research work(Oral care segmentation)- Price wise toothpaste can be segmented as economy, regular and value added segment. The price range varies from Rs. 15-20 for a 100gm pack in the economy segment. Rs30-35 for a $100 \mathrm{gm}$ pack in the regular segment and Rs 50 for $100 \mathrm{gm}$ pack in the value added segment. So analyzing economic factor is an important task for the company to fix the price

\subsection{Product attributes}

Based on this study product attributes also influencing the consumers for decision making. Most of the respondents gave importance to healthy tooth and gums, prevention of tooth decay, herbal attribute, whiteness, long lasting freshness, and good foam. So people consider the benefit of the product for buying toothpaste. This supported by the following review.

Vani, Ganesh and Panchanatham (2011) discussed the benefit of toothpaste in toothpaste buying model. In this article they discussed about decay prevention and brighter teeth.-Large number of families with children seriously concerned about the possibilities of cavities and shows a definite preference for fluoride toothpaste. Large group of young married people smoke more than average. They are giving importance to brighter teeth. So analyzing the requirement of people is important factor for selling the product successfully in the market

\subsection{Brand image}

Based on this study the preference for selecting toothpaste is mainly based on brand, $\mathrm{n}$ quality, and flavor. Brand image influencing the consumer mind and consumer feel the quality of the product. This is supported by the following review. Zeithaml, Parasuraman, and Berry (1985) suggested that the brand image was an extrinsic attribute of the product. He believed that the brand image has less impact 
compared to intrinsic attributes. Jacoby (1978) suggested that the brand image served as a channel for providing certain information to the customer. Roselily (1971) noted that the brand image was considered to be a consistently favorable factor as a risk reliever. Zinkhan \& Martin (1978) found that the consumer has a more positive attitude toward the product with a brand image than toward the product with no brand image.

\subsection{Reference group}

Based on this study parents are influencing more for buying toothpaste then friends, spouse, kids and self decision. So reference group also influencing the consumer in decision making. This is supported by the following review. Lamb, Hair \&McDaniel (1998) suggested that the reference group provided three types of influences. Informational influence, normative influence, and identification influence. Informational influence means that an individual uses the behavior and options of group member to gather useful information. Normative influence refers to an individual's achieving group expectations and gaining the respect of and sense of belonging to the group. Identification influence occurs when an individual internalizes the values and norms of the group.

\subsection{Advertising}

Based on this study majority of the respondents influenced by advertisement for buying toothpaste. In recent circumstances technology plays an important role in decision making; especially in advertising field the technology role is very high. Television advertisement inducing the consumer mind for decision making, especially kid's advertisement for toothpaste influencing the kids to influence the parents to buy a particular brand. Other kind of advertisement in magazine, newspaper also influencing the people. Advertising is a strong base for consumer to select toothpaste. Celebrity endorsement also influencing the consumer for decision making; attractive banner in road side attracts the consumer to select a particular brand. This is supported by the following review.

A successful nation economy depends on advertising promoting sales so that factory production is maintained, people are employed and have spending power, and the money goes round and round. Advertising, it has been conjectured in prior literature, shapes consumer preferences in multiple ways. The first, most obvious effect is that advertising informs the consumer of product attributes and hence raises awareness and knowledge of the true quality of the brand. This has been called the informative effect of advertising (Bucklin 1965, Lavidge and Steiner 1961).Second, advertising may directly influence a consumers brand evaluation through such cues as celebrity endorsements and music, even without providing any explicit information. This has been referred to as the persuasive or prestige effect of ads (Aaker \& Stayman, 1990, Batra \& Ray, 1986).Third, advertising can influence how consumers experience and evaluate the quality of the product from subsequent consumption. This effect has been evocatively referred to as the transformative effect of advertising (Deighton, 1984, 1988).

\subsection{Sales promotion}

Based on this study most of the respondents influenced by free gift, extra quantity and discount. So free gift influencing the customer for decision making. This is supported by the following review. Daly, Ellen in advertising impact using the power of promotional gifts. The power of promotional product rests with reciprocation. If the right gift is presented properly the recipient will want to give something back. So the free gift is an essential tool in promoting the product. Normally human being is attracted by any kind of free gift.

\subsection{Brand switching}

Based on this study switching of one brand to other brand is mainly based on advertisement impact and offers provided by the companies. Sudden increase in price also affected the respondents to switch .Some respondent's switch to other brand for trying new option. In some cases friends, kids, parents relatives influencing the people to switch. So promotion played an important role in switching. This is supported by the following review. Gupta (1988) concluded that more than $84 \%$ of the sales increase due to promotions is accounted for by brand switching (a very small part of which may be switching between different sizes of brands). . Bell et al. (1999) offer an empirical generalization on promotional response. They concluded that brand switching varies systematically across product categories

\section{Conclusion and Recommendation}

Consumer behavior is not exactly predicted one; somewhat it is predicted with the help of research activity. Starting and ending of the survey ends with only one statement 'consumer is king' .So the 
companies concentrate in analyzing the requirement of people thoroughly to satisfy and retaining the consumer. This study revealed that consumer awareness of toothpaste is less in Bangalore city. Oral care market offers huge potential as penetration and per capita consumption of oral care product is very low in India. However, rising per capita income and increasing awareness is driving demand of oral care products, the dentist population is also low in India. For promoting the product consumption and creating awareness government has taken initiative like dental health camps, Manufactures have used advertising campaigns to promote higher consumption of toothpaste. Creating the awareness is a part of social responsibility of the company. Most of the consumers are ready to accept the suggestion of dentist, so the government is also responsible for appointing more dentists to create the awareness. There are some important factors considered by the consumer for decision making. Brand image, advertising, and offer play an important role in purchasing toothpaste, sometimes based on the offer the consumer compare with competitor product and select the best one. Product attribute also analyzed by the consumer for deciding a brand. Switching of one product to other company product is mainly based on advertisement, brand name, packaging availability, and price rise, etc.

So the companies analyze all these factors and find out the best suitable tools for promoting their toothpastes in India.

The 1990s have borne witness to dramatic shifts in the marketplace triggered by sharp changes in the lifestyle patterns of the past and present and the radical revolution in the telecommunication technology. Time tested concepts on brand loyalty and Mass Marketing, are being turned on their heads as they fail to gauge the behavior of new generation customers. The behavior is characterized by the uniqueness of individual expectations, the preference for multiple options, propensity to abandon Brand loyalty and switch to competition Brands that give higher (perceived) value. The new breed is even willing to import to satisfy specific requirement. It is difficult to classify this generation consumers by conventional demographic factors and unless their thought process and buying behavior are fully understood, decisions on product designs and packaging, branding and distribution channels are likely to be misplaced. With the inevitability of change looming large over the horizon, Indian companies must learn from their western counterparts; not only to identify the sources, timing and direction of the changes likely to affect India, but also the new competencies and perspective that will enable them to respond to these changes, comprehensively and effectively. Companies offering Product or Services will need to understand this new face of the customers.

\section{Limitation}

Our study suffers from some limitation, which could be avenues for further research. This study failed to talk about about the psychographics of the consumer. Understanding psychographics of the consumer is an important tool to understand the inner feelings, and attitude of the consumer. The changing demographic profile of the population in terms of education, income, size of family and so on, are important by what will be more substantive in days to come will be the Psychographics of customers that is how they feel, think or behave. Marketers will have to constantly monitor and understand the underlying Psychographics to map their respective industries are moving and decide what needs to be done, by way of adding value that motivates customers to buy the company's products and influence the future industry structure. One more problem in this study was questionnaire. Most of the questions are closed ended it limits the respondents answer.

\section{References}

Assunçao, J.L., and Meyer, J.R., (1993): The Rational Effect of Price Promotions on sales and Consumption, Management Science, 39(5): 517-535.

Bawa, K., and Shoemaker. (1987): The Coupon-Prone Consumer: Some Findings Based on Purchase Behavior across Product Classes, Journal of Marketing, 51(4), 99-110.

Bell, D.R., Chiang, J., and Padmanabhan, D. (1999): The Decomposition of Promotional Response, Marketing Science, 18 (4): 504-526.

Daly, and Ellen. (1993): Advertising impact: Using the power of promotional gifts, The American Salesman, 38 (10):16.

Del Hawkins, I., Roger Best, J. \& Kenneth Coney, A. (2002): Consumer behaviour: Tata McGraw Hill Publishing Co Ltd: New Delhi 
Everything you wanted to know about toothpaste. Retrieved from www.saveyoursmile.com/toothpaste/toothpastea.html

Fader, P.S., and Lodish, L.M. (1990): A Cross-Category Analysis of Category Structure and Promotional Activity for Grocery Products. Journal of Marketing, 54 (4): 52-65.

Gupta, Sunil. (1988): Impact of sales promotions on when, what and how much to buy. Journal of Marketing Research, 25 (4): 342-355.

Harish, K. S. (2009): Consumer Motivation Perception. Marketing Mastermind, 9(12): 47-48.

Jacoby, J.. And Chestnut. (1978): Brand Loyalty, Measurement and Management. New York: John Wiley \& Sons.

Narasimhan, C. (1984): A price discrimination theory of coupons. Marketing Science, 3(2):128-147

Nitin Mehta, Xinlei(Jack) Chen,Om Narasimhan (2008): Informing, Transforming, and Persuading: Disentangling the Multiple Effects of Advertising on brand choice decision, Marketing Science 27(3):334

Rajendra, N. (2006): Market Research, New Delhi, ND: Tata McGraw Hills.

Stephanie N., M. (2001): Consumers channel preferences: An integrated model. Unpublished Doctoral dissertation, Isenberg school of management), Retrieved from Proquest database

Suja N., R. (2007): Consumer behavior in Indian perspective, Mumbai: Himalaya publishing House

Sumathi, S., \& Saranavel, P. (2003): Marketing Research \&Consumer Behavior, Vikas publishing house: New Delhi

The history of teeth cleaning, Retrieved from http://www.bbc.co.uk/dna/h2g2/A2818686

Tooth care products. Retrieved from http://www.bupa.co.uk/individuals/health-information

Vani, G., Ganesh, B., M., \& Panchanatham, N. (2009): Segmentation in Indian Oral care industry: An overview, SRM management digest

Vani, G., Ganesh B, M., \& Panchanatham, N. (2010): Oral care industry: Colgate’s smiley promos, Advertising Express

Wansink, B., and Desphande, R. (1994: .Out of Sight, Out of Mind: Pantry Stockpiling and Brand-Usage Frequency, Marketing Letters, 5(1): 91-100.

Zeithaml, V.A. (1988): Consumer Perceptions of Price, Quality, and Value: A Means-End Model and Synthesis of Evidence, Journal of Marketing, 52 (3): 2-22. 